\title{
Adverse events of colonoscopy in a colorectal cancer screening program with fecal immunochemical testing: a population-based observational study
}

\section{(ㄷ)(우우}

\author{
Authors \\ Bernard Denis ${ }^{1,2}$, Isabelle Gendre², Sarah Weber², Philippe Perrin²
}

Institutions

1 Department of Gastroenterology, Louis Pasteur Hospital, Colmar, France

2 ADECA Alsace, Colmar, France

submitted 27.6.2020

accepted after revision 22.10 .2020

\section{Bibliography}

Endoscopy International Open 2021; 09: E224-E232

DOI 10.1055/a-1324-2763

ISSN 2364-3722

(C) 2021. The Author(s).

This is an open access article published by Thieme under the terms of the Creative Commons Attribution-NonDerivative-NonCommercial License, permitting copying and reproduction so long as the original work is given appropriate credit. Contents may not be used for commecial purposes, or adapted, remixed, transformed or built upon. (https://creativecommons.org/licenses/by-nc-nd/4.0/)

Georg Thieme Verlag KG, Rüdigerstraße 14,

70469 Stuttgart, Germany

\section{Corresponding author}

Bernard Denis, Department of Gastroenterology, Louis Pasteur Hospital, 39 avenue de la Liberté, 68024, Colmar Cedex, France

Fax: + 33389124533

bernard.denis@ch-colmar.fr

\section{ABSTRACT}

Background and study aims The aim of this study was to assess adverse events (AEs) associated with colonoscopy in the French colorectal cancer screening program with fecal occult blood test (FOBT).

Patients and methods A retrospective cohort study was performed of all colonoscopies performed from 2015 to 2018 for a positive fecal immunochemical test (FIT) in patients aged 50 to 74 years within the screening program in progress in Alsace, part of the French program. AEs were recorded through prospective voluntary reporting by community gastroenterologists and retrospective postal surveys addressed to individuals screened. They were compared with those recorded in the previous program following colonoscopies performed from 2003 to 2014 for a positive guaiac-based FOBT (gFOBT).

Results Of 9576 colonoscopies performed for a positive FIT, 6194 (64.7\%) were therapeutic. Overall, 180 AEs were recorded $(18.8 \%$, $95 \% \mathrm{Cl} 16.1-21.5), 114$ of them $(11.9 \%$, $95 \% \mathrm{Cl}$ 9.7-14.1) requiring hospitalization, 55 (5.7\%, $95 \%$ $\mathrm{Cl} 4.2-7.3)$ hospitalization $>24$ hours, and eight $(0.8 \%$, $95 \% \mathrm{Cl} 0.3-1.4)$ surgery. The main complications requiring hospitalization were perforation $(n=18,1.9 \%$, $95 \% \mathrm{Cl} 1.0$ $2.7)$ and bleeding ( $n=31,3.2 \%, 95 \% \mathrm{Cl} 2.1-4.4)$. Despite a significant increase in several risk factors for complication, the rate of AEs remained stable between gFOBT and FIT programs. Overall, we observed one death $(1 / 27,000$ colonoscopies) and three splenic injuries.

Conclusions The harms of colonoscopy in a colorectal cancer screening program with FIT are more frequent than usually estimated. This study revealed six AEs requiring hospitalization $>24$ hours (three bleeds, two perforations), one necessitating surgery, and 50 minor complications per 1000 colonoscopies.

\section{Introduction}

Colorectal cancer (CRC) is the third most common cancer and the second leading cause of cancer death worldwide [1]. Most CRCs are preventable. Several randomized controlled trials (RCTs) have demonstrated the efficacy of screening with guaiac-based fecal occult blood test (gFOBT) and flexible sigmoidoscopy on CRC mortality [2]. Many countries have thus launched gFOBT CRC screening programs [3]. The positive im- pact of screening with a fecal immunochemical test (FIT) on CRC mortality is not demonstrated through RCTs but the superiority of FIT over gFOBT is now well established, so that many countries, including France, are now organizing FIT CRC screening programs instead of gFOBT programs [3]. However, the risk/benefit balance of these programs have been poorly evaluated [4]. On one hand, none of the population-based screening programs with gFOBT have been able to reproduce the CRC mortality reduction promised by the RCTs, and the expected 
benefit of population-based screening programs with FIT has yet to be quantified. On the other hand, the risk of screening trials and programs with gFOBT and FIT has been poorly evaluated [5]. We demonstrated that adverse events (AEs) associated with colonoscopy were underestimated in all RCTs with gFOBT and the rate is higher in a real-world program [6]. The rate of $\mathrm{AEs}$ requiring hospitalization was estimated at $7.0 \%$ and $10.0 \%$ in two FIT CRC screening pilots, notably higher than the upper limit of $5 \%$ recommended by the European Society of Gastrointestinal Endoscopy (ESGE) [7-9]. Some risk factors for AEs, such as increasing age, number of comorbidities, use of anticoagulation, performance by non-gastroenterologist endoscopist, polypectomy, and polyp number, size and location are well established $[6,7,10]$. Consequently, and because the neoplasia yield is significantly higher, we speculated that AEs would be more prevalent in FIT-positive colonoscopies than in gFOBT-positive colonoscopies and, a fortiori, than in direct screening colonoscopies $[10,11]$. Valid real-world data are needed to inform target populations, caregivers, policymakers, and funders [4].

Our aim was to assess colonoscopy-related AEs in the CRC screening program organized in France using FIT and to compare them with those of the previous gFOBT program.

\section{Patients and methods}

We retrospectively analyzed AEs associated with all colonoscopies performed in residents undergoing colonoscopy for a positive FOBT within the population-based CRC screening program organized in Alsace, a region of 1.8 million inhabitants in eastern France, and part of the French national program. The FOBT was a gFOBT from September 2003 to July 2014 and quantitative FIT was used from May 2015 to January 2018.

\section{FOBT screening program}

A gFOBT CRC screening program was initiated in Alsace in 2003. Its design has been previously described $[12,13]$. Residents aged 50 to 74 years ( 0.57 million individuals) were invited by mail every other year to participate. The gFOBT (Hemoccult II) was replaced by an FIT (OC-Sensor) in May 2015. The positivity threshold was set at $30 \mu \mathrm{g}$ of hemoglobin per gram of feces so that the positivity rate would be $4 \%$ to $5 \%$. People with a positive FOBT were referred for colonoscopy.

All certified endoscopists, i.e. all gastroenterologists, participated in the program. Colonoscopies were performed as usual by community gastroenterologists, without special conditions linked to the fact that the procedure followed a positive FOBT within the organized screening program, generally with sedation/anesthesia provided by an anesthesiologist. Diagnostic colonoscopy was defined as colonoscopy without intervention or with cold biopsy, whereas therapeutic colonoscopy corresponded to any procedure with polypectomy, regardless of technique. Conventional adenomas, sessile serrated adenomas/polyps, and traditional serrated adenomas were considered neoplastic polyps, whereas hyperplastic polyps were nonneoplastic polyps. Advanced adenoma was defined as an ade- noma measuring $\geq 10 \mathrm{~mm}$ or with a villous component $>20 \%$ or with high-grade dysplasia.

\section{Adverse event recording}

AEs of all initial colonoscopies were recorded; those for surveillance colonoscopies were excluded. Information on AEs came from two main sources: prospective voluntary AE reports from gastroenterologists (either directly on the colonoscopy report or on a separate dedicated sheet) and seven retrospective postal surveys (every other year). For the postal surveys, all individuals who had undergone a colonoscopy received a mailed questionnaire with a prepaid envelope for reply. The questionnaire asked for information on any colonoscopy-related AE and its consequences. The investigators reviewed all AEs with a phone call to the patient, and/or the general practitioner and/or the gastroenterologist. All colonoscopy reports and hospital charts documenting serious AEs were reviewed.

\section{Adverse event classification}

AEs were classified according to the American Society for Gastrointestinal Endoscopy (ASGE) lexicon [14]. All events definitely, probably, and possibly related to colonoscopy occurring within 30 days of the colonoscopy were taken into account, whereas events unlikely related were not. An event that prevented completion of the planned procedure and/or resulted in admission to the hospital, prolongation of an existing hospital stay, another procedure needing sedation/anesthesia, or subsequent medical consultation was considered an AE. Unplanned events that did not interfere with completion of the planned procedure or change the plan of care were considered incidents. Bleeding that occurred and was managed during the procedure was considered as an incident. We added three indicators: $A E$ requiring hospitalization, $A E$ requiring $>24$-hour hospitalization, and $A E$ necessitating surgery. The judgment on causality and severity was made by the two first authors (BD and IG).

\section{Endpoints}

The primary endpoint was to estimate the incidence and severity of AEs following FIT-positive colonoscopies performed within the current CRC screening program, overall and for each $A E$ category. The secondary aim was to compare them with those following gFOBT-positive colonoscopies performed within the previous program.

\section{Statistical methods}

We calculated the incidence of complications per 1000 colonoscopies and $95 \%$ confidence intervals $(95 \% \mathrm{Cl})$ using the binomial distribution (Wald). The chi-squared test was used to test for statistical significance by comparisons of proportions. All statistical tests were two-sided. The significance threshold was set at 0.05 . Statistical analysis was performed with Excel 2013 (Microsoft). 
- Table 1 Comparison between the two periods of screening with guaiac-based fecal occult blood test and quantitative fecal immunochemical test.

\begin{tabular}{|c|c|c|c|}
\hline & $\begin{array}{l}\text { gFOBT } \\
(2003-2014)\end{array}$ & $\begin{array}{l}\text { FIT } \\
(2015-2018)\end{array}$ & $\mathbf{P}$ \\
\hline \multicolumn{4}{|l|}{ Population } \\
\hline - Number of people & 17,152 & 9061 & - \\
\hline - Mean age (SD) years & $62.6(7.0)$ & $63.0(7.1)$ & $<0.001$ \\
\hline - Men n (\%) & $9525(55.5)$ & $5452(60.2)$ & $<0.001$ \\
\hline - Postal survey participation n (\%) & $11.519(67.2)$ & $4605(50.8)$ & $<0.001$ \\
\hline \multicolumn{4}{|l|}{ Colonoscopies } \\
\hline - Number of colonoscopies & 17,871 & 9576 & - \\
\hline - Therapeutic colonoscopies n (\%) & $8700(48.7)$ & $6194(64.7)$ & $<0.001$ \\
\hline - Invasive cancer n (PPV) & $1086(6.3)$ & $469(5.2)$ & $<0.001$ \\
\hline - Advanced adenoma $n$ (PPV) & $3957(23.1)$ & $3209(35.4)$ & $<0.001$ \\
\hline - Adenoma $\geq 10 \mathrm{~mm} \mathrm{n} \mathrm{(PPV)}$ & $3630(21.2)$ & $2840(31.3)$ & $<0.001$ \\
\hline - Adenoma n (PPV) & $6431(37.5)$ & $5002(55.2)$ & $<0.001$ \\
\hline - Non-neoplastic polyps n (PPV) & $1637(9.5)$ & $783(8.6)$ & 0.02 \\
\hline \multicolumn{4}{|l|}{ Polyps } \\
\hline - Number of polyps & 18,443 & 15,553 & - \\
\hline - Number of polypectomies & 17,614 & 15,059 & - \\
\hline - Mean number of polypectomies per therapeutic colonoscopy (SD) & $2.0(1.6)$ & $2.4(2.0)$ & $<0.001$ \\
\hline - Proximal polyps n (\% of polyps) & $5336(28.9)$ & $5591(35.9)$ & $<0.001$ \\
\hline - Polyps $\geq 2 \mathrm{~cm} \mathrm{n}$ (\% of polyps) & $1588(8.6)$ & $864(5.6)$ & $<0.001$ \\
\hline - Surgery for benign polyps $n$ (\% of individuals) & $247(1.4)$ & $161(1.8)$ & 0.04 \\
\hline \multicolumn{4}{|l|}{ Complications } \\
\hline - Incidents² n (\%) & $618(34.6)$ & $349(36.4)$ & 0.4 \\
\hline - Adverse events ${ }^{2}$ (\%) & $425(23.8)$ & $180(18.8)$ & 0.01 \\
\hline - Mild² AEs n (\%) & $342(19.1)$ & $123(12.8)$ & 0.001 \\
\hline - Moderate ${ }^{2}$ AEs n (\%) & $57(3.2)$ & $40(4.2)$ & 0.2 \\
\hline - Severe ${ }^{2}$ AEs n (\%) & $26(4.5)$ & $17(1.8)$ & 0.5 \\
\hline - AEs without hospitalization and incidents n (\%) & $852(47.7)$ & $415(43.3)$ & 0.1 \\
\hline - AEs requiring hospitalization n (\%) & $191(10.7)$ & $114(11.9)$ & 0.4 \\
\hline - AEs requiring hospitalization $>24 \mathrm{hr} \mathrm{n}(\%)$ & $94(5.3)$ & $55(5.7)$ & 0.6 \\
\hline - AEs necessitating surgery n (\%) & $19(1.0)$ & $8(0.8)$ & 0.6 \\
\hline - Perforations n (\%) & $20(1.1)$ & $18(1.9)$ & 0.1 \\
\hline - Bleeding n (\%) & $69(3.9)$ & $43(4.5)$ & 0.4 \\
\hline
\end{tabular}

\section{Results}

\section{Colonoscopies and yield}

Overall, 434,633 individuals were invited, 194,975 (44.9\%) participated and 9,450 (4.8\%) had a positive FIT with subsequent
95.9\% adherence to colonoscopy (9061 individuals; mean age 63.0 years; SD 7.1) ( $\triangleright$ Table 1 ). A total of 9576 colonoscopies were performed by 114 community gastroenterologists. The most advanced lesions detected during therapeutic colonoscopies (64.7\% of colonoscopies) were cancer (4.7\%), neoplastic 
- Table 2 Classification of complications and their severity during the fecal immunochemical test period.

\begin{tabular}{|c|c|c|c|}
\hline & $\begin{array}{l}\text { Diagnostic colonoscopies } \\
n=3382 \\
\text { number }(\%)[95 \% \mathrm{Cl}]\end{array}$ & $\begin{array}{l}\text { Therapeutic colonoscopies } \\
\mathrm{n}=6194 \\
\text { number }(\%)[95 \% \mathrm{Cl}]\end{array}$ & $\begin{array}{l}\text { All colonoscopies } \\
\mathbf{n}=9576 \\
\text { number }(\%)[95 \% \mathrm{Cl}]\end{array}$ \\
\hline Incidents ${ }^{1}$ & 56 (16.6) [12.3-20.9] & $293(47.3)[42.0-52.6]$ & $349(36.4)[32.7-40.2]$ \\
\hline Adverse events $^{1}$ & $26(7.7)[4.7-10.6]$ & $154(24.9)[21.0-28.7]$ & $180(18.8)[16.1-21.5]$ \\
\hline Mild ${ }^{1}$ & $19(5.6)[3.1-8.1]$ & $104(16.8)[13.6-20.0]$ & $123(12.8)[10.6-15.1]$ \\
\hline Moderate $^{1}$ & $1(0.3)[0-0.9]$ & $39(6.3)[4.3-8.3]$ & $40(4.2)[2.9-5.5]$ \\
\hline Severe $^{1}$ & $6(1.8)[0.4-3.2]$ & $11(1.8)[0.7-2.8]$ & $17(1.8)[0.9-2.6]$ \\
\hline Adverse events requiring hospitalization & $11(3.3)[1.3-5.2]$ & $103(16.6)[13.4-19.8]$ & $114(11.9)[9.7-14.1]$ \\
\hline Bleeding overall & - & $43(6.9)[4.9-9.0]$ & $43(4.5)[3.2-5.8]$ \\
\hline Bleeding requiring hospitalization & - & $31(5.0)[3.2-6.8]$ & $31(3.2)[2.1-4.4]$ \\
\hline Perforation (all requiring hospitalization) & $3(0.9)[0-1.9]$ & $15(2.4)[1.2-3.6]$ & $18(1.9)[1.0-2.7]$ \\
\hline Perforation requiring hospitalization $>24 \mathrm{hr}$ & $3(0.9)[0-1.9]$ & $12(1.9)[0.8-3.0]$ & $15(1.6)[0.8-2.4]$ \\
\hline
\end{tabular}

polyp (83.0\%), and non-neoplastic polyps (12.3\%). A total of 15,059 polyps were removed, that is, a mean number of 2.4 polyps per therapeutic colonoscopy.

\section{Adverse events}

Overall, 180 AEs (18.8\% colonoscopies; 95\% Cl 16.1-21.5) were recorded in 178 patients. The rate of AEs did not differ between men (18.4\%) and women (19.5\%) $(P=0.7)$ but increased significantly with age: $13.4 \%$ in people aged 50 to 59 , $20.6 \%$ in those 60 to 69 , and $23.5 \%$ in those 70 to 75 ( $P=$ $0.02)$. The rate of AEs requiring hospitalization was $11.9 \%$ (95\% Cl 9.7-14.1), 16.6\% for therapeutic and 3.3\% for diagnostic colonoscopies $(P<0.0001)$ ( $>$ Table 2 ). It was $5.7 \%$ (95\% Cl 4.2-7.3) for $>24$-hour hospitalization, $7.3 \%$ for therapeutic and $3.0 \%$ for diagnostic colonoscopies $(P=0.008)$. It varied from $0 \%$ to $50.0 \%$ depending on the endoscopist, with no correlation with the endoscopist's adenoma detection rate or annual colonoscopy volume. The mean length of stay was 3.5 days (SD 5.5): overnight admission $(n=59)$, stay of 2 or 3 days $(n=23)$ and stay $>3$ days $(n=32)$. The rate of AEs necessitating surgery was $0.8 \%$ o $(95 \% \mathrm{Cl} 0.3-1.4), 0.6 \%$ for therapeutic and $1.2 \%$ for diagnostic colonoscopies $(P=0.4)(\triangleright$ Table 2$)$. No deaths occurred.

One $A E$ requiring $>24$-hour hospitalization was encountered for 51.6 individuals harboring at least one adenoma $\geq 10 \mathrm{~mm}$ (58.3 one advanced adenoma).

\section{Perforations}

A total of 18 perforations were recorded, that is a rate of $1.9 \%$ (95\% Cl 1.0-2.7), 3 (0.9\%) for diagnostic and 15 (2.4\%) for therapeutic colonoscopies ( $\triangleright$ Table 2 ). Severity was moderate in five cases $(28 \%)$ and severe in eight $(44 \%)$. All required hospitalization, 15 (1.6\%) hospitalization $>24$ hours, and seven $(0.7 \%$ ) surgery (mean length of stay 12 days). Eleven (61\%) perforations were diagnosed immediately; eight (44\%) being immediately closed by the endoscopist (mean length of stay 2.5 days). The diagnosis of perforation was delayed in seven cases (39\%) (mean length of stay 8.9 days), four of them being operated on. Thirteen (72\%) perforations were caused by polypectomy, seven (39\%) of them during a second colonoscopy performed by an "expert" for a large polyp (30 to $70 \mathrm{~mm}$ ) that a first endoscopist had been unable to remove. Three perforations were caused by mechanical disruption of the sigmoid colon wall due to the progression of the colonoscope and two perforations were caused by barotrauma. Four of them were operated on.

\section{Hemorrhage}

Overall, 46 delayed hemorrhages were recorded, three were classified as an incident and 43 as an AE (4.5\%). Severity was moderate in 29 cases (63\%) and severe in four (9\%). All were caused by polypectomy, so that the rate of bleeding requiring hospitalization was $3.2 \%$, $0 \%$ for diagnostic and $5.0 \%$ for therapeutic colonoscopies $(2.3 \%, 0 \%$ and $3.4 \%$ respectively for hospitalization>24 hours) (mean length of stay 3.5 days) ( $\triangleright$ Table 2). Blood loss led to transfusion in nine cases (21\%), repeat endoscopy in 30 (70\%), endoscopic therapy in 23 (53\%), and surgery in none $(0 \%)$.

\section{Other adverse events}

Two splenic injuries were observed, one operated on and one treated with embolization ( $\vee$ Table 3 ). One postpolypectomy syndrome was managed conservatively. Two cases of cardiac dysrhythmia secondary to hypokalemia caused by the bowel preparation were encountered, as were one case each of myocardial infarction, pulmonary embolism, and aspiration pneumonia. Overall, 349 incidents (36.4\%) were recorded, so that the rate of incidents and AEs without hospitalization was $43.3 \%$ o (95\% Cl 39.3-47.4). 
- Table 3 Adverse events requiring hospitalization during the two periods of screening with guaiac-based fecal occult blood test and quantitative fecal immunochemical test.

\begin{tabular}{|c|c|c|c|}
\hline & $\begin{array}{l}\text { gFOBT }(2003-2014) \\
n=17,871 \text { colonoscopies } \\
\text { number }(\%)[95 \% \mathrm{Cl}]\end{array}$ & $\begin{array}{l}\text { FIT }(2015-2018) \\
n=9576 \text { colonoscopies } \\
\text { number }(\%)[95 \% \mathrm{CI}]\end{array}$ & $\mathbf{P}$ \\
\hline GASTROINTESTINAL AES & $175(9.8)[8.3-11.2]$ & $104(10.9)[8.8-12.9]$ & 0.4 \\
\hline Bleeding & $54(3.0)[2.2-3.8]$ & $31(3.2)[2.1-4.4]$ & 0.8 \\
\hline Perforation & $20(1.1)[0.6-1.6]$ & $18(1.9)[1.0-2.7]$ & 0.1 \\
\hline Post-polypectomy syndrome & $7(0.4)[0.1-0.7]$ & $4(0.4)[0-0.8]$ & 0.9 \\
\hline Splenic injury & $1(0.1)[0-0.2]$ & $2(0.2)[0-0.5]$ & 0.3 \\
\hline Overnight surveillance & $80(4.5)[3.5-5.5]$ & $46(4.8)[3.4-6.2]$ & 0.7 \\
\hline Other & $13(0.7)[0.3-1.1]$ & $3(0.3)[0-0.7]$ & 0.2 \\
\hline NON-GASTROINTESTINAL AES & $16(0.9)[0.5-1.3]$ & $10(1.0)[0.4-1.7]$ & 0.7 \\
\hline Total & 191 (10.7) [9.2-12.2] & $114(11.9)[9.7-14.1]$ & 0.4 \\
\hline
\end{tabular}

- Table 4 Differences between the two surveys on screening with quantitative fecal immunochemical test.

\begin{tabular}{|l|l|l|}
\hline & First survey & Second survey \\
\hline Number of colonoscopies & $\mathrm{n}=4907$ & $\mathrm{n}=4669$ \\
\hline Response rate $\mathrm{n}(\%)$ & $1646(33.5 \%)$ & $3266(70.0 \%)$ \\
\hline AEs without hospitalization and incidents $\mathrm{n}(\%)$ & $170(34.6)$ & $245(52.5)$ \\
\hline AEs requiring hospitalization $\mathrm{n}(\%)$ & $53(10.8)$ & $61(13.1)$ \\
\hline AEs requiring hospitalization $>24 \mathrm{hr} n(\%)$ & $23(4.7)$ & $32(6.9)$ \\
\hline AEs necessitating surgery $\mathrm{n}(\%)$ & $3(0.6)$ & $5(1.1)$ \\
\hline Perforations requiring hospitalization $>24$ hr $\mathrm{n}(\%)$ & $6(1.2)$ & $9(1.9)$ \\
\hline Bleeding requiring hospitalization $>24$ hr $\mathrm{n}(\%)$ & $8(1.6)$ & $14(3.0)$ \\
\hline Non-gastrointestinal AEs requiring hospitalization $>24$ hr $\mathrm{n}(\%)$ & $4(0.8)$ & $4(0.9)$ \\
\hline AE, adverse event. & & 0.3 \\
\hline
\end{tabular}

\section{Sources of information}

A total of 4912 (51.3\%) people answered the surveys. The prepaid reply envelope was mistakenly omitted for the first FIT survey so that the answer rate was significantly reduced (33.5\%) compared to that of the second FIT survey (70.0\%) $(P<$ $0.00001)$. The rates of AEs, perforations, and bleeding requiring hospitalization $>24$ hours did not differ between the two surveys, whereas the rate of incidents and AEs without hospitalization was significantly higher in the second survey $(52.5 \%$ vs $34.6 \%$; $P<0.01$ ) ( Table 4 ). Overall, $85.1 \%$ of AEs requiring hospitalization were identified by the gastroenterologists: $85.0 \%$ of perforations, $78.8 \%$ of bleeds, and $37.5 \%$ of non-gastrointestinal AEs.

\section{Comparison between gFOBT and FIT-positive colonoscopies}

Several risk factors for complications increased significantly in the FIT period: rate of therapeutic colonoscopies, rate of proximal polyps and mean number of polyps per therapeutic colonoscopy ( $\triangleright$ Table 1$)$. The overall rate of AEs decreased significantly from 23.8 to $18.8 \%$ o $(P=0.01)$, whereas that of AEs requiring hospitalization did not differ significantly (from 10.7 to $11.9 \%, P=0.4)$. The rates of AEs requiring hospitalization related to therapeutic colonoscopies (from 19.8 to $16.6 \%, P=0.1$ ), of gastrointestinal AEs (from 4.3 to $5.3 \%, P=0.2$ ) and non-gastrointestinal AEs (from 0.4 to $0.6 \%, P=0.4$ ) did not differ significantly. Endoscopic management of perforations increased significantly from $30 \%$ to $61 \%(P=0.05)$ and all cases of bleeding were managed endoscopically in the FIT period. 
Table 5 Adverse events requiring hospitalization in different population-based studies of colorectal cancer screening programs.

\begin{tabular}{|c|c|c|c|c|c|c|c|c|}
\hline Screening & Country & Years & $\begin{array}{l}\text { Number of co- } \\
\text { lonoscopies }\end{array}$ & $\begin{array}{l}\text { Polypectomy } \\
\text { rate }\end{array}$ & $\begin{array}{l}\text { Adverse } \\
\text { events }\end{array}$ & $\begin{array}{l}\text { Perfora- } \\
\text { tion }\end{array}$ & $\begin{array}{l}\text { Bleed- } \\
\text { ing }\end{array}$ & $\begin{array}{l}\text { AA/ } \\
\text { AE24 }\end{array}$ \\
\hline \multirow[t]{3}{*}{ FIT } & Alsace (France) & 2015-18 & 9576 & $65 \%$ & $11.9 \%$ & $1.9 \%$ & $3.2 \%$ & 58 \\
\hline & Basque country $[7,15]$ & 2009-14 & 39254 & $70 \%$ & $10.0 \%$ & $2.7 \%$ & $6.2 \%$ & 38 \\
\hline & Denmark [8] & 2014 & 14712 & $55 \%$ & $6.9 \%$ & $1.0 \%$ & $4.1 \%$ & $\mathrm{~N} / \mathrm{A}$ \\
\hline \multirow[t]{3}{*}{ gFOBT } & England (BCSP) [16] & $2006-9$ & 36460 & $47 \%$ & $7.2 \%$ & $0.9 \%$ & $4.1 \%$ & $\mathrm{~N} / \mathrm{A}$ \\
\hline & England (BCSP) [10] & $2006-12$ & 130831 & $53 \%$ & $14.2 \%$ & $0.6 \%$ & $6.5 \%$ & $\mathrm{~N} / \mathrm{A}$ \\
\hline & Scotland (SBoCP) [17] & 2007-14 & 53332 & $46 \%$ & $4.7 \%$ & $0.8 \%$ & $3.7 \%$ & $\mathrm{~N} / \mathrm{A}$ \\
\hline Colonoscopy & Austria [18] & $2007-10$ & 44350 & $34 \%$ & $2.5 \%$ & $0.1 \%$ & $1.2 \%$ & 9 \\
\hline
\end{tabular}

AA/AE24, number of persons harboring at least one advanced adenoma per adverse event requiring hospitalization > 24 hours; FIT, fecal immunochemical test; gFOBT, guaiac-based fecal occult blood test; N/A, not available; BCSP, English Bowel Cancer Screening Program; SBoCP, Scottish Bowel Screening Program.

One death occurred during the whole gFOBT and FIT period, that is, one death for 27.447 colonoscopies (30-day mortality $3.6 / 100.000$ colonoscopies) in a 57-year-old man.

\section{Discussion}

In our population-based community-based CRC screening program with FIT, the rate of AEs requiring hospitalization was $11.9 \%$ overall, $1.9 \%$ ofor perforation and $3.2 \%$ for bleeding. The rate of AEs requiring hospitalization $>24$ hours was $5.7 \%$, $1.6 \%$ for perforation and $2.2 \%$ for bleeding. The rate of AEs necessitating surgery was $0.8 \%, 0.7 \%$ for perforation and $0 \%$ for bleeding. Gastrointestinal AEs requiring hospitalization and hospitalization $>24$ hours remained stable during the gFOBT and FIT periods despite a significant increase in several risk factors for complications: the rate of therapeutic colonoscopies increased from $48.7 \%$ to $64.7 \%$, the mean number of polypectomies per therapeutic colonoscopy from 2.0 to 2.4 , and the rate of proximal polyps from $28.9 \%$ to $35.9 \%$. Compared with the gFOBT period, the need for surgical management of AEs decreased significantly during the FIT period, from $70.0 \%$ to $38.9 \%$ for perforation and from $4.3 \%$ to $0 \%$ for bleeding. During the whole gFOBT and FIT period, we observed one death (30day mortality $1 / 27,000$ colonoscopies) and three splenic injuries (1/9000 colonoscopies).

The harm caused by colonoscopies in our FIT program is in line with that recently reported by two other programs ( $\triangleright \mathbf{T a -}$ ble 5) $[7,8,15-18]$. Their rates of $7.0 \%$ and $10.0 \%$, along with our $11.9 \%$ rate of complications requiring hospitalization, are notably higher than the maximum standard of $5 \%$ for 7 day hospital admission/readmission rate recommended by the ESGE [9]. They were higher than those usually reported, that is $0.5 \%$ for perforation and $2.6 \%$ for bleeding in a systematic review and meta-analysis of 21 studies, along with those reported in another review of six studies on colonoscopies for stoolpositive testing, i.e. $0.8 \%$ for perforation and $1.9 \%$ o for bleeding $[19,20]$. Nevertheless, the comparison with such recommendations and aggregated figures is not pertinent as there is considerable heterogeneity in the literature. A quick reading might suggest that French endoscopists' performances are poor. Such is probably not the case and has to be evaluated. However, today, it is almost impossible to compare different series dealing with colonoscopy-related AEs because indication and yield are different; $A E$ nomenclature and sources of information are different; rates of referral for surgery are different. Even within a single program, AE rates vary twofold: e. g. from $7.2 \%$ to $14.2 \%$ in the English Bowel Cancer Screening Program (BCSP) $[10,16]$.

Neoplasia yield is correlated with the risk of complication and increases significantly depending on the indication for colonoscopy (symptoms, direct screening, positive gFOBT, positive FIT) $[6,7]$. The rate of therapeutic colonoscopies varies more than twofold between series, from $32.9 \%$ in the German colonoscopy screening program [21] to around $50 \%$ in gFOBT programs and $55 \%$ to $70 \%$ in FIT programs [7,8]. A way to compare different series is to analyse separately diagnostic and therapeutic colonoscopies. For diagnostic colonoscopies, our perforation and bleeding rates requiring hospitalization were $0.9 \%$ and $0 \%$, in line with those reported in the meta-analysis ( $0.4 \%$ and $0.6 \%$, respectively) [19]. For therapeutic colonoscopies, comparison is possible only between series having similar indications and neoplasia yields. Our 5.0\% rate of bleeding requiring hospitalization was significantly lower than the $9.8 \%$ reported in the meta-analysis [19]. By contrast, our perforation rate was $2.4 \%$, significantly higher than the $0.8 \%$ in the metaanalysis [19]. Our high rate is probably related to the high number of polyps per therapeutic colonoscopy (2.4), their large size ( $5.6 \%$ of polyps $\geq 2 \mathrm{~cm}$ ), their proximal location (35.9\%) and the low rate of surgical resection of benign polyps (1.8\%). This level of neoplasia yield is seldom encountered, almost exclusively in FIT-positive colonoscopies. The rate of polyp(s) $\geq 2 \mathrm{~cm}$ was $2.1 \%$ in the English gFOBT BCSP [22]. The rate of patients with at least one polyp $\geq 2 \mathrm{~cm}$ was $1.1 \%$ in the Austrian colonoscopy screening program (7.4\% in our program) [18].

Gastrointestinal AEs can be expected to be more prevalent today with AEs related to endoscopic mucosal resection of numerous, large and right-sided polyps. In fact, during our FIT period, all bleeding episodes were managed endoscopically. 
Moreover, the rate of perforations managed endoscopically increased significantly from $30 \%$ to $61 \%$ between the gFOBT and FIT periods. In the latter period, $39 \%$ of perforations were probably inevitable, caused by an "expert endoscopist" during large polypectomies. Almost half (45\%) were diagnosed immediately and managed endoscopically, the median length of the hospital stay being 2.5 days. These figures indicate that in recent years in Alsace community gastroenterologists have improved their performance level significantly. One might wonder whether accredited gastroenterologists could perform better. In the French and Scottish screening programs, colonoscopies are performed by any certified community gastroenterologist, whereas in England and the Netherlands they are performed by a set number of accredited gastroenterologists [17].

Our findings suggest that the rate of AEs is significantly higher in a community-based population-based FIT CRC screening program than usually reported $[19,20,23]$. The invited population should be informed for improved shared decisionmaking. Today, the leaflet accompanying the letter inviting the French population to participate in FIT CRC screening mentions in tiny characters that serious colonoscopy-related AEs are rare, estimated at $3 \%$. The word "serious" is not further explained. Maintaining this figure that underestimates by a factor of two the true prevalence of AEs is a kind of propaganda. It must be updated. We propose this statement "Colonoscopy-related AEs, mainly bleeding and perforation, are rare. It is estimated that for 1000 colonoscopies performed for a positive FIT, six complications requiring hospitalization longer than 24 hours and one complication necessitating surgery will occur."

The ASGE lexicon is essential as it is almost the only one to propose a standardized nomenclature for AEs [14]. However, it is not satisfactory for common use: it is rather complex so that it has to be detailed every time it is used; it is best suited for the United States healthcare system; and certain criteria are somewhat arbitrary and open to criticism $[6,10,16,23]$. Moreover, it does not define any specific method for identifying AEs. The less one seeks, the less one finds. All studies that rely on voluntary reporting underestimate actual complication rates [8,24]. In our study, $15 \%$ of AEs requiring hospitalization were not reported by gastroenterologists. In Germany, the AE rate was threefold higher in an audit than in the national colonoscopy screening registry [24]. The Danish CRC screening database registered only $29.4 \%$ of recognized complications [8]. A survey directed toward all patients should be mandatory for the publication of any article dealing with AEs. Moreover, should we still be calling a perforation occurring during a large polypectomy that is immediately diagnosed, closed and under surveillance $<48$ hours in hospital a complication? There is an imperative and urgent need for a worldwide consensus on AE nomenclature, collection and reporting. An international task force should be created to formulate a series of recommendations, standardize definitions and categories, develop standardized methodology to search for AEs, and establish rules for reporting endoscopy-related AEs, for the same reasons and in the same way as were established the consensus on post-colonoscopy CRC and the STROBE statement [25]. In anticipation, we adopted three simple, precise, self-explanatory indicators, all relevant for patient information: AEs requiring hospitalization, as it is the most commonly used criterion to define clinically relevant complications; AEs requiring hospitalization $>24$ hours, as we feel that an overnight admission for surveillance after colonoscopy (around $50 \%$ of our hospitalizations) is not a true complication; and AEs necessitating surgery.

Rate of referral for surgery must also be considered. An AE following the treatment of a large sessile polyp is attributed either to endoscopy or to surgery depending on the type of resection. Surgical resection-related morbidity-mortality is significantly higher than endoscopic polypectomy-related morbidity-mortality $[26,27]$. Consequently, if the rate of referral for surgery for benign polyps is high, the individual endoscopist's or CRC screening program's colonoscopy-related AE rate will be low while the overall AE rate will be high. Unfortunately, the rate of referral for surgery is never specified in articles concerning colonoscopy-related AEs and results of CRC screening programs. Yet, it is far from negligible as surgery for benign colorectal polyps represents $25 \%$ of surgeries for colorectal neoplasia in the USA, [28] and surgery-related morbidity-mortality is almost entirely preventable, provided the endoscopist who encounters a polyp he/she cannot manage personally refers the patient to an "expert endoscopist" rather than to a surgeon. "Expert endoscopists" are able to endoscopically remove more than $90 \%$ of large polyps [26]. Overall, all studies concerning AEs of colonoscopy series and CRC screening programs should mention their rate of referral for surgery for benign polyps (or, failing that, mention their surgery-related AEs). The rate of referral for surgery was $1.8 \%$ in our program, about half that reported in Brittany (4.1\%) [29]. Our low rate of surgical resection may partly explain our high rate of perforations following therapeutic colonoscopies.

The main strengths of our study are the population- and community-based setting along with the direct patient surveys. Indeed, this study is one of the first to assess the harms of colonoscopy in a population-based FIT CRC screening program. It is also noteworthy that the details of all AEs were confirmed through direct access to hospital charts, colonoscopy reports, and, whenever necessary, phone calls to the gastroenterologist and/or the general practitioner and/or the patient. This study is not without limitations. The response rate to the patient survey was $51.3 \%$, low in comparison with the $83.7 \%$ for the NHS BCSP, and hospitalization claims for the period could not be analyzed, so that some AEs may have been missed, leading to potential underestimation of the rate of AEs [10]. However, the low response rate resulted in underestimation only of incidents and AEs that did not require hospitalization, without consequence for $A E s$ requiring hospitalization, hospitalization $>24$ hours, and surgery.

Therefore, underestimation of clinically relevant AEs is probably less of an issue. Another limitation is that the postal surveys were performed every other year, so that the delay between colonoscopy and survey could be long for some patients. Likewise, this delay may have induced an underestimation of incidents and AEs without hospitalization as patients may have forgotten some minor complications. 
The risk/benefit balance of CRC screening remains to be assessed correctly $[4,5]$. At a time when most countries are organizing CRC screening programs, there is an urgent need for a worldwide consensus on standardized indicators. Overall, owing to the risk factors of colonoscopy-related AEs (polyp number and size) the risk is roughly proportionate to the benefit. We propose a new indicator that is the number of individuals harboring at least one adenoma $\geq 10 \mathrm{~mm}$ per $\mathrm{AE}$ requiring hospitalization > 24 hours (that could be abbreviated A10 +/AE24). Between our gFOBT and FIT programs, A10+/AE24 increased from 39 to 52 . This indicator would be the cornerstone for assessment and comparison of the benefit-risk balance of different CRC screening programs (e.g. between different countries) and strategies (e.g. between FIT and colonoscopy screening programs). Unfortunately, this indicator cannot be calculated in any previous study, so we presented another close indicator in $>$ Table 5, that is the number of individuals who harbor an advanced adenoma per $A E$ requiring hospitalization $>24$ hours.

\section{Conclusions}

AEs associated with FIT-positive colonoscopies are more frequent than usually reported, estimated in our program at six AEs requiring hospitalization $>24$ hours (three bleeds, two perforations), one necessitating surgery, and 50 minor complications per 1000 procedures. The invited population should be openly informed of these figures. Overall, there is a lack of transparency, both in the medical literature and in the information delivered to the population, about the risk/benefit balance of CRC screening [4]. Almost all of the gastroenterology literature states that colonoscopy is safe and serious complications are uncommon $[19,20,23]$. Our results indicate that the price to be paid to save lives through CRC screening programs is higher than what is stated in most pilots. Nevertheless, the risk/benefit balance of CRC screening remains favorable, estimated in our FIT program at 52 individuals harboring at least one adenoma $\geq 10 \mathrm{~mm}$ per $\mathrm{AE}$ requiring hospitalization $>24$ hours. And finally, the heterogeneity of series dealing with colonoscopy-related AEs is so enormous that comparison becomes almost impossible. There is an imperative and urgent need for a worldwide consensus on AE nomenclature, collection and reporting.

\section{Acknowledgments}

The authors thank all the general practitioners who participated in this screening program, the participating gastroenterologists and pathologists for their contributions, and all the staff of ADECA Alsace (Association pour le dépistage du cancer colorectal en Alsace).

\section{Competing interests}

The authors declare that they have no conflict of interest.

\section{References}

[1] GBD 2017 Colorectal Cancer Collaborators. The global, regional, and national burden of colorectal cancer and its attributable risk factors in 195 countries and territories, 1990-2017: a systematic analysis for the Global Burden of Disease Study 2017. Lancet Gastroenterol Hepatol 2019; 4: 913-933

[2] Holme $\emptyset$, Bretthauer M, Fretheim A et al. Flexible sigmoidoscopy versus faecal occult blood testing for colorectal cancer screening in asymptomatic individuals. Cochrane Database Syst Rev 2013; 9: CD009259. Review

[3] Senore C, Basu P, Anttila A et al. Performance of colorectal cancer screening in the European Union Member States: data from the second European screening report. Gut 2019; 68: 1232-1244

[4] Bretthauer M, Kalager M, Adami HO. Do's and don'ts in evaluation of endoscopic screening for gastrointestinal cancers. Endoscopy 2016; 48: $75-80$

[5] Heleno B, Thomsen MF, Rodrigues DS et al. Quantification of harms in cancer screening trials: literature review. BMJ 2013; 347: f5334. Review

[6] Denis B, Gendre I, Sauleau EA et al. Harms of colonoscopy in a colorectal cancer screening programme with faecal occult blood test: a population-based cohort study. Dig Liver Dis 2013; 45: 474-480

[7] Arana-Arri E, Imaz-Ayo N, Fernández MJ et al. Screening colonoscopy and risk of adverse events among individuals undergoing fecal immunochemical testing in a population-based program: A nested casecontrol study. United European Gastroenterol J 2018; 6: 755-764

[8] Mikkelsen EM, Thomsen MK, Tybjerg J et al. Colonoscopy-related complications in a nationwide immunochemical fecal occult blood test-based colorectal cancer screening program. Clin Epidemiol 2018; 10: 1649-1655

[9] Kaminski MF, Thomas-Gibson S, Bugajski M et al. Performance measures for lower gastrointestinal endoscopy: a European Society of Gastrointestinal Endoscopy (ESGE) Quality Improvement Initiative. Endoscopy 2017; 49: 378-397

[10] Rutter MD, Nickerson C, Rees C] et al. Risk factors for adverse events related to polypectomy in the English Bowel Cancer Screening Programme. Endoscopy 2014; 46: 90-97

[11] Robertson DJ, Lee JK, Boland CR et al. Recommendations on Fecal Immunochemical Testing to Screen for Colorectal Neoplasia: A Consensus Statement by the US Multi-Society Task Force on Colorectal Cancer. Gastroenterology 2017; 152: 1217-1237

[12] Denis B, Ruetsch M, Strentz P et al. Short-term outcomes of the first round of a pilot colorectal cancer screening programme with guaiac based faecal occult blood test. Gut 2007; 56: 1579-1584

[13] Denis B, Gendre I, Perrin P. Participation in four rounds of a French colorectal cancer screening programme with guaiac faecal occult blood test: a population-based open cohort study. J Med Screen 2015; 22: 76-82

[14] Cotton PB, Eisen GM, Aabakken L et al. A lexicon for endoscopic adverse events: report of an ASGE workshop. Gastrointest Endosc 2010; 71: 446-454

[15] Portillo I, Idigoras I, Bilbao I et al. Colorectal cancer screening program using FIT: quality of colonoscopy varies according to hospital type. Endosc Int Open 2018; 6: E1149-E1156

[16] Lee TJ, Rutter MD, Blanks RG et al. Colonoscopy quality measures: experience from the NHS Bowel Cancer Screening Programme. Gut 2012; 61: 1050-1057

[17] Quyn AJ, Fraser CG, Stanners G et al. Scottish Bowel Screening Programme colonoscopy quality - scope for improvement? Colorectal Dis 2018; 20: 277-283 
[18] Ferlitsch M, Reinhart K, Pramhas S et al. Sex-specific prevalence of adenomas, advanced adenomas, and colorectal cancer in individuals undergoing screening colonoscopy. JAMA 2011; 306: 1352-1358

[19] Reumkens A, Rondagh EJ, Bakker CM et al. Post-colonoscopy complications: a systematic review, time trends, and meta-analysis of population-based studies. Am J Gastroenterol 2016; 111: 1092-1101

[20] Lin JS, Piper M, Perdue LA et al. Screening for Colorectal Cancer: An Updated Systematic Review for the US Preventive Services Task Force: Evidence Synthesis No. 135. Rockville, MD: Agency for Healthcare Research and Quality; 2016: AHRQ publication 14-05203-EF-1

[21] Pox CP, Altenhofen L, Brenner $\mathrm{H}$ et al. Efficacy of a nationwide screening colonoscopy program for colorectal cancer. Gastroenterology 2012; 142: 1460-1467

[22] Lee TJ, Rees C], Nickerson C et al. Management of complex colonic polyps in the English Bowel Cancer Screening Programme. Br J Surg 2013; 100: 1633-1639

[23] Ko CW, Riffle S, Michaels L et al. Serious complications within 30 days of screening and surveillance colonoscopy are uncommon. Clin Gastroenterol Hepatol 2010; 8: 166-173
[24] Adler A, Lieberman D, Aminalai A et al. Data quality of the German screening colonoscopy registry. Endoscopy 2013; 45: 813-818

[25] Rutter MD, Beintaris I, Valori R et al. World Endoscopy Organization Consensus Statements on Post-Colonoscopy and Post-Imaging Colorectal Cancer. Gastroenterology 2018; 155: 909-925

[26] Hassan C, Repici A, Sharma P et al. Efficacy and safety of endoscopic resection of large colorectal polyps: a systematic review and metaanalysis. Gut 2016; 65: 806-820

[27] de Neree Tot Babberich MPM, Bronzwaer MES, Andriessen JO et al. Outcomes of surgical resections for benign colon polyps: a systematic review. Endoscopy 2019; 51: 961-972

[28] Peery AF, Cools KS, Strassle PD et al. Increasing rates of surgery for patients with nonmalignant colorectal polyps in the United States. Gastroenterology 2018; 154: 1352-1360

[29] Le Roy F, Manfredi S, Hamonic S et al. Frequency of and risk factors for the surgical resection of non-malignant colorectal polyps: a population-based study. Endoscopy 2016; 48: 263-270 